\title{
Engineering the heterogeneous interfaces of inverse opals to boost charge transfer for efficient solar water splitting
}

\author{
Miaomiao Zhang ${ }^{1 \dagger}$, Pianpian Liu ${ }^{1 \dagger}$, Hao Tan ${ }^{2}$, Hui Zhang ${ }^{1}$, Fangzhi Huang ${ }^{1 *}$, Kun Zhang ${ }^{3}$ and Shikuo Li $^{{ }^{*}}$
}

\begin{abstract}
Herein, we report a three-dimensional porous $\mathrm{TiO}_{2} / \mathrm{Fe}_{2} \mathrm{TiO}_{5} / \mathrm{Fe}_{2} \mathrm{O}_{3}$ (TFF) inverse opal through in situ thermal solid reactions for photoelectrochemical water splitting. The $\mathrm{Fe}_{2} \mathrm{TiO}_{5}$ interfacial layer within TFF acting as a bridge to tightly connect to $\mathrm{TiO}_{2}$ and $\mathrm{Fe}_{2} \mathrm{O}_{3}$ reduces the interfacial charge transfer resistance, and suppresses the bulk carrier recombination. The optimized TFF displays a remarkable photocurrent density of $0.54 \mathrm{~mA} \mathrm{~cm}^{-2}$ at $1.23 \mathrm{~V}$ vs. reversible hydrogen electrode (RHE), which is 25 times higher than that of $\mathrm{TiO}_{2} / \mathrm{Fe}_{2} \mathrm{O}_{3}$ (TF) inverse opal $\left(0.02 \mathrm{~mA} \mathrm{~cm}^{-2}\right.$ at $1.23 \mathrm{~V}$ vs. $\mathrm{RHE}$ ). The charge transfer rate in TFF inverse opal is 2-8 times higher than that of TF in the potential range of 0.7 $-1.5 \mathrm{~V}$ vs. RHE. The effects of the $\mathrm{Fe}_{2} \mathrm{TiO}_{5}$ interfacial layer are further revealed by $\mathrm{X}$-ray absorption spectroscopy and intensity-modulated photocurrent spectroscopy. This work offers an interfacial engineering protocol to improve charge separation and transfer for efficient solar water splitting.
\end{abstract}

Keywords: interfacial engineering, heterojunction, transfer resistance, inverse opal, solar water splitting

\section{INTRODUCTION}

Water splitting by photoelectrochemical (PEC) technology is an attractive way to obtain sustainable hydrogen fuel [1-3]. The design of suitable nanostructures is critical for developing highefficiency photoelectrodes under visible light irradiation. Many strategies have been proposed to improve the solar-to-hydrogen (STH) conversion efficiency, such as elemental doping [4,5], heterojunctions $[6-8]$, defects $[9,10]$, and interfacial engineering [11]. As an alternative protocol, interface engineering is thought to be an effective method, with strong bonding or electronic interactions, greatly boosting the charge separation and hindering the charge recombination to enhance STH efficiency $[12,13]$. Interfacial engineering has been widely used to manipulate photo-induced charge transport in photoactive composite materials for photovoltaic devices and photocatalysts.

Three-dimensional (3D) inverse opal with periodic porous structure is a promising skeletal material for light harvesting because of the "slow photon effect" [14-16]. Attempts have been made to deposit different photocatalytic components on the "host" to build various interfacial heterojunctions including type I heterojunctions, Schottkey junctions, and Ohmic junctions. These can promote photo-induced charge separation and transportation [17-20]. Some excellent nanostructures can be found in the literature with considerable improvement for PEC performance, such as CdS nanorod@ $\mathrm{SnO}_{2}$ nanobowl [21], $\mathrm{Fe}_{2} \mathrm{O}_{3}$ nanorod@nanobowl [22], 3D g- $\mathrm{C}_{3} \mathrm{~N}_{4} / \mathrm{Ni}(\mathrm{OH})_{2} \quad$ [23], $\mathrm{WO}_{3} /$ $\mathrm{BiVO}_{4} / \mathrm{Co}-\mathrm{Pi}$ inverse opal [24], and fluorine-doped tin oxide (FTO)/FTO-nanocrystal/ $/ \mathrm{TiO}_{2}$ inverse opal [25]. However, heterogeneous interfaces in the composite photocatalysts can lead to inappropriate energy band arrangements that result in serious charge recombination because of the undesired barriers. The interface of two solids usually introduces a thermal boundary resistance in Ohmic contact, which is challenging for charge transfer. Engineering the heterogeneous interfaces with tunable energy band position is advantageous for suppressing charge recombination and promoting transportation of majority carriers. In particular, the transfer distance of minority carriers to semiconductor/electrolyte interface can be largely reduced in the $3 \mathrm{D}$ porous inverse opal architectures. Thus, it is necessary to design and modulate heterogeneous interfaces with 3D composite inverse opal architecture to obtain an optimal synergistic PEC performance.

Herein, we developed a $3 \mathrm{D}$ hierarchical $\mathrm{TiO}_{2} / \mathrm{Fe}_{2} \mathrm{TiO}_{5} / \mathrm{Fe}_{2} \mathrm{O}_{3}$ (TFF) inverse opal through in situ thermal solid reactions between $\mathrm{TiO}_{2}$ and $\mathrm{Fe}_{2} \mathrm{O}_{3}$ for efficient solar water splitting. Compared with the $\mathrm{TiO}_{2} / \mathrm{Fe}_{2} \mathrm{O}_{3}$ (TF) inverse opal, the $\mathrm{Fe}_{2} \mathrm{TiO}_{5}$ interfacial layer within TFF inverse opal acts as a strong "adhesive" to form low-resistance heterogeneous interfaces. As expected, the photocurrent density of the optimized hierarchical TFF inverse opal achieves $0.54 \mathrm{~mA} \mathrm{~cm}^{-2}$ at $1.23 \mathrm{~V} v s$. reversible hydrogen electrode (RHE), which is higher than that of TF inverse opal $\left(0.02 \mathrm{~mA} \mathrm{~cm}^{-2}\right.$ at $1.23 \mathrm{~V} v s$. RHE). Moreover, the separation efficiency is as high as $61.0 \%$ for the TFF inverse opal. The electrochemical and intensity-modulated photocurrent spectroscopy (IMPS) analysis demonstrates that the PEC activity enhancement is mainly due to the $\mathrm{Fe}_{2} \mathrm{TiO}_{5}$ interfacial layer, which promotes the interfacial carrier transfer and suppresses the bulk recombination of the electron-hole pairs. This work

\footnotetext{
${ }^{1}$ Anhui Province Key Laboratory of Chemistry for Inorganic/Organic Hybrid Functionalized Materials, Key Laboratory of Structure and Functional Regulation of Hybrid Materials (Anhui University) Ministry of Education, School of Chemistry and Chemical Engineering, Institute of Physical Science and Information Technology, Anhui University, Hefei 230601, China

${ }^{2}$ National Synchrotron Radiation Laboratory, University of Science and Technology of China, Hefei 230029, China

${ }^{3}$ Bengbu Institute of Product Quality Supervision and Inspection Research, Bengbu 233040, China

$\dagger$ These authors contributed equally to this work.

*Corresponding authors (emails: lishikuo@ahu.edu.cn (Li S); hfz@ahu.edu.cn (Huang F))
} 
may provide potential strategy to design heterogeneous interfaces of novel photoelectrodes for effective PEC water splitting.

\section{EXPERIMENTAL SECTION}

\section{Catalysts preparation}

Synthesis of $3 \mathrm{D}$ periodic porous $\mathrm{TiO}_{2}$ inverse opal The uniform $3 \mathrm{D} \mathrm{TiO}_{2}$ inverse opal was synthesized through a sol-gel method using immersed and self-assembled polystyrene (PS) spheres as reported with a slight modification [26]. The $\mathrm{TiO}_{2}$ precursor solution contained $0.5 \mathrm{~mL}$ of tetrabutyl titanate, $0.8 \mathrm{~mL}$ of $\mathrm{HCl}, 4 \mathrm{~mL}$ of ethanol and $1.6 \mathrm{~mL}$ of deionized water.

\section{Synthesis of hierarchical TFF inverse opal}

The hierarchical TFF inverse opal was synthesized by a hydrothermal method. In detail, the $\mathrm{TiO}_{2}$ inverse opals were kept in $30 \mathrm{~mL}$ different concentration solutions of $\mathrm{FeCl}_{3} \cdot 6 \mathrm{H}_{2} \mathrm{O}(10,20$ and $30 \mathrm{mmol} \mathrm{L}^{-1}$ ) in a $50-\mathrm{mL}$ autoclave at $100^{\circ} \mathrm{C}$ for $6 \mathrm{~h}$ and labeled as TFF-10, TFF-20, and TFF-30 inverse opals, respectively. Yellow $\mathrm{FeOOH}$ nanoparticles were formed on the surface of the $\mathrm{TiO}_{2}$ inverse opal. The $\mathrm{TiO}_{2} / \mathrm{FeOOH}$ inverse opals were then annealed at $550^{\circ} \mathrm{C}$ for $2 \mathrm{~h}$ and additional $15 \mathrm{~min}$ at $750^{\circ} \mathrm{C}$ to synthesize the hierarchical TFF inverse opals. The TF inverse opals were synthesized by annealing at $400^{\circ} \mathrm{C}$ for $2 \mathrm{~h}$.

\section{Characterization}

Scanning electron microscopy (SEM) images were recored using a FIELD SEM S-4800 at an acceleration voltage of $5 \mathrm{kV}$. Transmission electron microscopy (TEM) images were obtained by JEM-2100-TEM with an accelerating voltage of $200 \mathrm{kV}$. A powder X-ray diffraction (XRD) pattern was analyzed on an Xray polycrystalline diffractometer Smart Lab 9KW with graphitemonochromated $\mathrm{Cu} \mathrm{Ka}$ radiation $(\lambda=1.54056 \AA)$. Ultravioletvisible (UV-vis) spectra were measured using a spectrophotometer (Hitachi U-4100) equipped with an integrating sphere. X-ray photoelectron spectroscopy (XPS) was recorded using an ESCALab MKII spectrometer with $\mathrm{Al} \mathrm{Ka}(1486.6 \mathrm{eV})$ as the X-ray source. Fe and Ti L-edge X-ray absorption near-edge structure (XANES) spectra were collected at the BL12B-a beamline of the National Synchrotron Radiation Laboratory.

\section{PEC measurements}

PEC measurements were performed in $1 \mathrm{~mol} \mathrm{~L}^{-1} \mathrm{KOH}$ solution ( $\mathrm{pH}$ 13.6) on an electrochemical workstation (CHI660E), using the standard three-electrode configuration ( $\mathrm{Pt}$ as the counter, $\mathrm{Ag} / \mathrm{AgCl}$ as the reference). The as-prepared heterojunction samples $(1.0 \mathrm{~cm} \times 1.0 \mathrm{~cm})$ used as the working electrodes were immersed into the electrolyte and irradiated under a $300-\mathrm{W}$ xenon lamp equipped with an AM 1.5 filter. The light power intensity at the sample positions was adjusted into $100 \mathrm{~mW} \mathrm{~cm}^{-2}$ using calibrated silicon solar cells. The electrolyte was purged with Ar gas for $30 \mathrm{~min}$ before the measurements. Linear-sweep voltammetry (LSV) scan rate was adjusted into $10 \mathrm{mV} \mathrm{s}^{-1}$. The stability measurements were performed at $1.23 \mathrm{~V} v s$. RHE. Electrochemical impedance spectroscopy (EIS) was carried out by using Zahner IM6 (Zahner Elektrik, Kronach, Germany) in a frequency range of $10 \mathrm{kHz}$ to $0.1 \mathrm{~Hz}$ with an amplitude of $10 \mathrm{mV}$ under simulated solar light illumination. Photocurrent spectra were acquired at an applied potential of $1.23 \mathrm{~V} v s$. RHE with $1 \mathrm{~nm}$ steps in the range of $365-800 \mathrm{~nm}$ using a Zahner IM6 equipment with light emitting diode (LED) lamps.

\section{RESULTS AND DISCUSSION}

The 3D porous TFF inverse opals were characterized by SEM and TEM. Fig. S1 shows the SEM image of the $\mathrm{TiO}_{2}$ inverse opal with a pore size of about $200 \mathrm{~nm}$ largely formed on FTO glass via a sol-gel process. The periodic $3 \mathrm{D}$ porous $\mathrm{TiO}_{2}$ nanostructure is a promising "host" for anchoring composite architectures. As shown in Fig. 1a-c and Fig. S2, numerous tiny nanoparticles were uniformly deposited on the porous skeleton after subsequent hydrothermal and thermal treatments. As the amount of $\mathrm{FeCl}_{3}$ increased, the surface particles became large and dense on the substrate skeleton. The sample presented a periodically porous nanostructure from top to bottom (Fig. 1d). Such a wellordered 3D hierarchical nanostructure not only offered a large

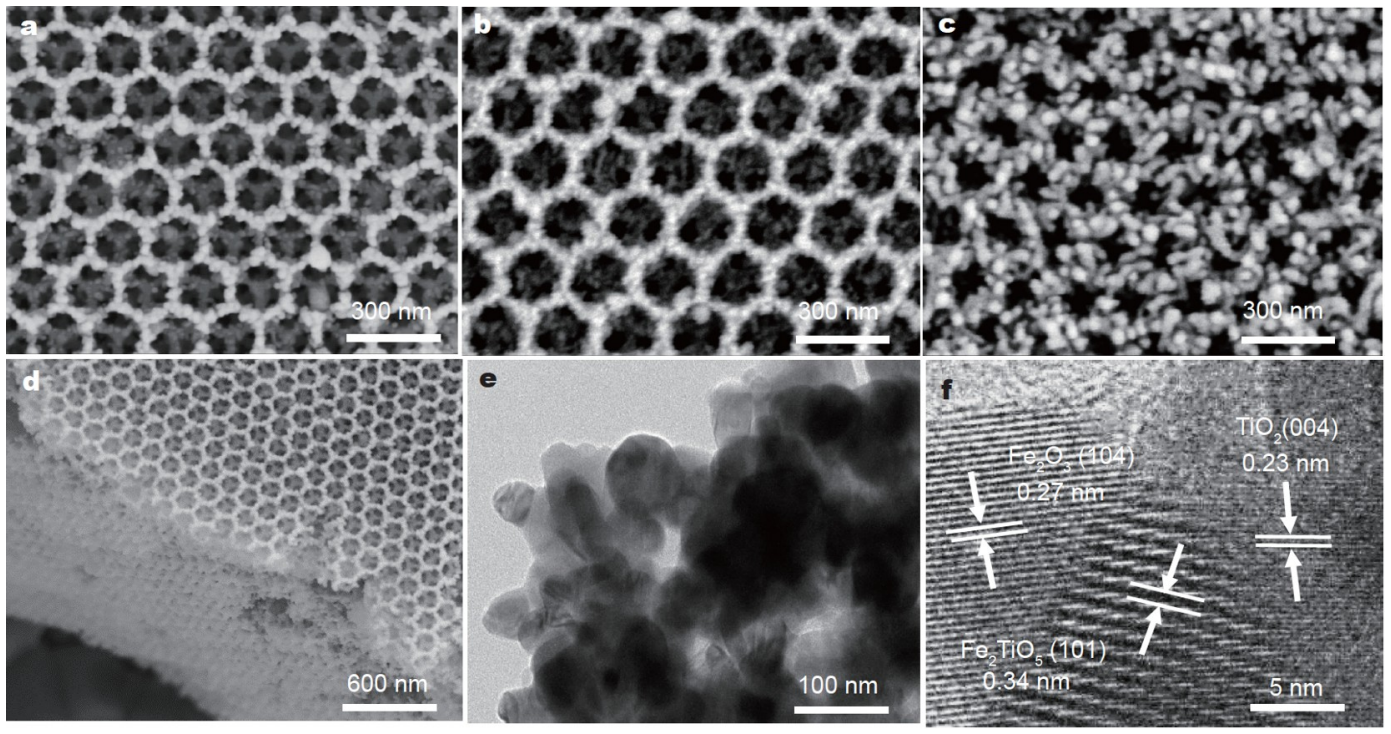

Figure 1 SEM images of TFF samples obtained with different amounts of $\mathrm{FeCl}_{3}$ precursors: TFF-10 (a), TFF-20 (b), and TFF-30 (c). Cross-sectional SEM image of TFF-20 (d) and TEM (e), and high-resolution TEM image of TFF-20 (f). 
surface for photon harvesting but also provided a short carrier transfer distance. The hierarchical configuration was further confirmed by TEM analysis. As displayed in Fig. 1e, numerous nanoparticles with a size of ca. $40 \mathrm{~nm}$ can be seen. They were compactly connected to each other to form a porous structure, and the intimate contact alleviated interface's resistance to charge transfer [27]. High-resolution TEM images (Fig. 1f) show lattice fringes with a d-spacing of $0.23,0.34$, and $0.27 \mathrm{~nm}$ ascribed to the (004), (101) and (104) planes of $\mathrm{TiO}_{2}, \mathrm{Fe}_{2} \mathrm{TiO}_{5}$, and $\mathrm{Fe}_{2} \mathrm{O}_{3}$, respectively [28]. Moreover, the $\mathrm{Fe}_{2} \mathrm{TiO}_{5}$ interfacial layer can act as a bridge, tightly connected to $\mathrm{TiO}_{2}$ and $\mathrm{Fe}_{2} \mathrm{O}_{3}$ in the sandwich structure.

The engineered heterogeneous interfaces provide a pathway for charge transfer and yield excellent PEC performance. The heterostructured inverse opals were further characterized using XRD, Raman, XPS and X-ray absorption fine structure (XAFS) measurements to obtain the chemical composition of each component. XRD patterns (Fig. S3) show the typical diffraction peaks of anatase (JCPDS:21-1271) and hematite (JCPDS:330664) $[29,30]$. However, no characteristic peaks of the $\mathrm{Fe}_{2} \mathrm{TiO}_{5}$ were observed, possibly because of the low component content in the sample. To confirm the presence of the $\mathrm{Fe}_{2} \mathrm{TiO}_{5}$ layer in the sandwich structure, Raman measurements (Fig. 2a) were employed. As seen, the peaks located at 224, 242.5, 291.5, 408.0, $499.3,608.1$ and $656.2 \mathrm{~cm}^{-1}$ correspond to $\alpha-\mathrm{Fe}_{2} \mathrm{O}_{3}$. Noticeably, the peaks at 660.1 , and $787.8 \mathrm{~cm}^{-1}$ are the sensitive peaks, and show a slight redshift when $\mathrm{Fe}$ is replaced by other elements [31]. The new peak appeared at $660.1 \mathrm{~cm}^{-1}$ and can be attributed to the redshift of the peak at $656.2 \mathrm{~cm}^{-1}$, evidencing the presence of $\mathrm{Fe}_{2} \mathrm{TiO}_{5}$ layer in the heterostructured sandwich inverse opal. Fig. S4 exhibits XPS of the heterostructured inverse opal. Fe, Ti and $\mathrm{O}$ elements were detected in the survey spectrum (Fig. S4a). The high resolution XPS spectra show that Fe $2 \mathrm{p}$ peaks were centered at 711 and $725 \mathrm{eV}$, which can be ascribed to the Fe $2 \mathrm{p}_{3 / 2}$ and $\mathrm{Fe} 2 \mathrm{p}_{1 / 2}$ as shown in Fig. S4c, demonstrating the presence of $\mathrm{Fe}^{3+}$ in the TFF inverse opal [26]. Fig. S4b shows the peaks located at 458.8 and $464.4 \mathrm{eV}$ corresponding to $\mathrm{Ti} 3 \mathrm{p}_{3 / 2}$ and
Ti $3 p_{1 / 2}$, respectively. The $\mathrm{O} 1 \mathrm{~s}$ spectra (Fig. S4d) can be deconvoluted into two peaks at 530 and $531.6 \mathrm{eV}$, respectively. Compared with the TF sample, the peaks of Fe $2 p$ and Ti $3 p$ of TFF shifted to a higher binding energy, indicating the electrondeficient state, possibly aroused by the charge transfer between the $\mathrm{Fe}_{2} \mathrm{TiO}_{5}$ and $\mathrm{Fe}_{2} \mathrm{O}_{3} / \mathrm{TiO}_{2}$. As seen, the Ti $\mathrm{L}_{3}$-edge (peaks $\mathrm{P}_{1}-$ $\mathrm{P}_{3}$ ) and $\mathrm{L}_{2}$-edge (peaks $\mathrm{P}_{4}$ and $\mathrm{P}_{5}$ ) in Fig. $2 \mathrm{~b}$ are due to electronic transition from the spin-orbit split $\mathrm{Ti} 2 \mathrm{p}_{3 / 2}$ and $2 \mathrm{p}_{1 / 2}$ initial states to the $\mathrm{Ti} 3 \mathrm{~d}$ final states, respectively [32]. For both $\mathrm{Ti} \mathrm{L}_{2}$ and $\mathrm{L}_{3}$ edges, the $3 \mathrm{~d}$ band splitting produced $\mathrm{t}_{2 \mathrm{~g}}\left(\mathrm{P}_{1}\right.$ and $\left.\mathrm{P}_{4}\right)$ and $\mathrm{e}_{\mathrm{g}}\left(\mathrm{P}_{2}\right.$, $\mathrm{P}_{3}$, and $\mathrm{P}_{5}$ ) sub-bands. Further, the $\mathrm{e}_{\mathrm{g}}$ sub-band splited into two peaks $\left(\mathrm{P}_{2}\right.$ and $\left.\mathrm{P}_{3}\right)$. For the TFF sample, it showed a spectral shape similar to $\mathrm{TiO}_{2}$ and $\mathrm{TF}$ samples, while a single peak located at the center between $\mathrm{P}_{2}$ and $\mathrm{P}_{3}$ can be observed, possibly aroused by the $\mathrm{Fe}_{2} \mathrm{TiO}_{5}$ phase $[33,34]$. In Fig. 2c, the two main lines of the $\mathrm{L}_{3}$ and $\mathrm{L}_{2}$-edges were located at $\sim 710$ and $\sim 723 \mathrm{eV}$, which are due to electronic transition of $\mathrm{Fe} 2 \mathrm{p}_{3 / 2}$ and $2 \mathrm{p}_{1 / 2}$ core electrons, splited by the spin-orbit interaction of the Fe $2 p$ core level, to an unoccupied $3 \mathrm{~d}$ level highly hybridized with the oxygen $2 \mathrm{p}$ orbital, respectively [34]. In comparison with the control samples ( $\mathrm{TF}$ and $\mathrm{Fe}_{2} \mathrm{O}_{3}$ ), the Fe L-edge peak of the TFF sample slightly shifted to lower energy, indicating the interfacial interactions of $\mathrm{Fe}_{2} \mathrm{TiO}_{5}$ with $\mathrm{Fe}_{2} \mathrm{O}_{3} / \mathrm{TiO}_{2}$ in the sandwich structure. The UV-vis diffuse reflectance spectra (DRS) of the TF and TFF samples are shown in Fig. $2 \mathrm{~d}$. The TF inverse opals displayed strong light absorption from ca. $608.2 \mathrm{~nm}$, corresponding to the band edge of $\mathrm{Fe}_{2} \mathrm{O}_{3}$ [30]. After combining with the $\mathrm{Fe}_{2} \mathrm{TiO}_{5}$ interfacial layer, the curve was slightly redshifted to $620.1 \mathrm{~nm}$, indicating that the light-harvesting ability was enhanced by coupling of the $\mathrm{Fe}_{2} \mathrm{TiO}_{5}$ interfacial layer due to the interface coupling effect [35] (Fig. 2e), which might promote interfacial carrier separation for PEC water splitting. As seen, an obvious Bragg reflection peak centered at $413 \mathrm{~nm}$ is observed for TFF inverse opal due to the slow light effect in Fig. S5.

The PEC performance of the TFF inverse opals was characterized as shown in Fig. 3 under $100 \mathrm{~mW} \mathrm{~cm}^{-2}$ light illumination. The photocurrent density of the optimized TFF inverse
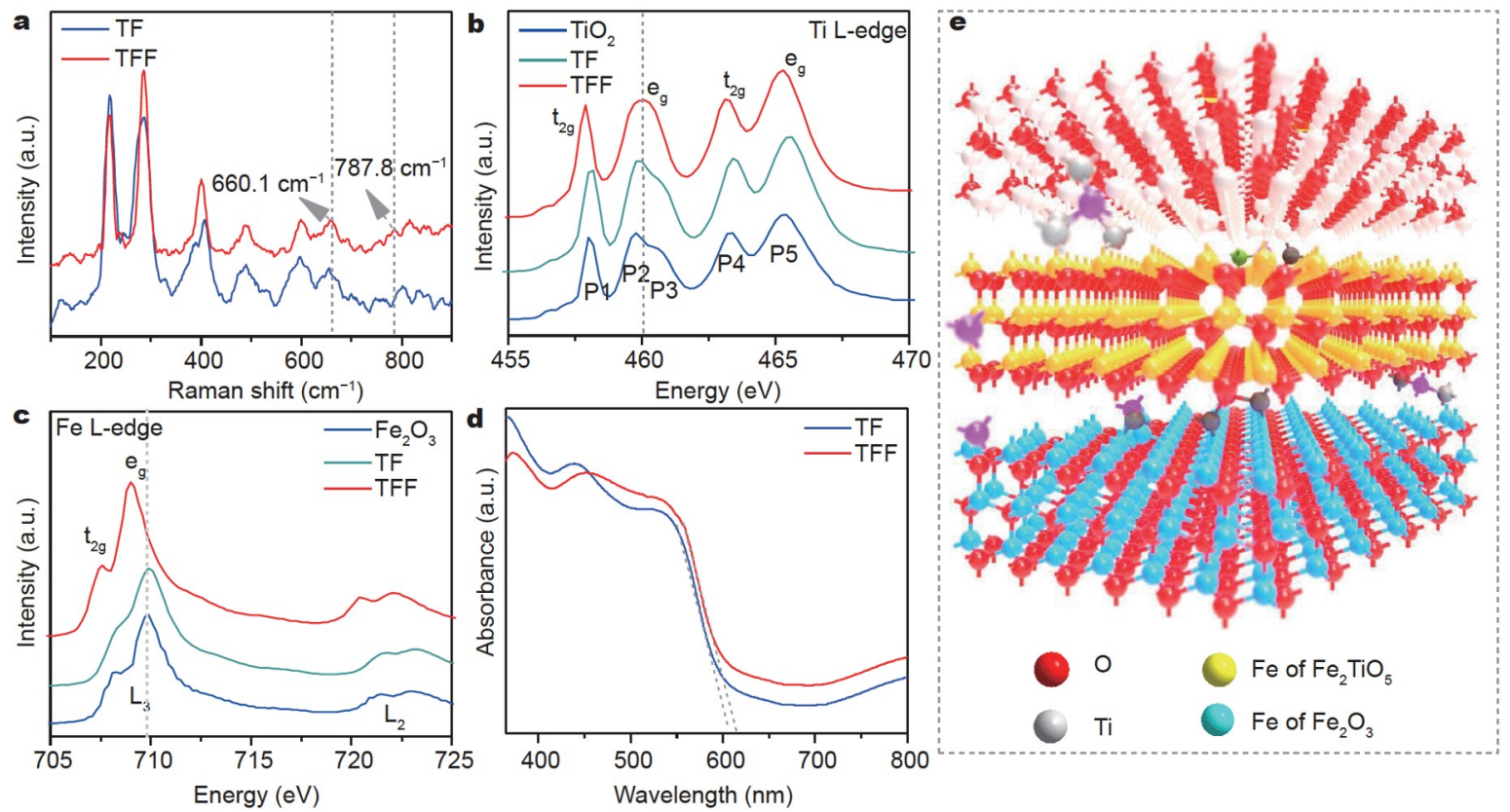

Figure 2 Raman spectra (a), Ti L-edge spectra (b), Fe L-edge spectra (c), UV-vis DRS (d) and interface schematic (e) of TF and TFF-20 samples. 
opal sample is ca. $0.54 \mathrm{~mA} \mathrm{~cm}^{-2}$ at $1.23 \mathrm{~V}$ vs. RHE (Fig. 3a), which is a remarkable improvement of 25 -fold relative to the TF inverse opal sample $\left(0.02 \mathrm{~mA} \mathrm{~cm}^{-2}\right.$ at $1.23 \mathrm{~V} v s$. RHE), implying that better charge separation or transfer in the TFF inverse opal with $\mathrm{Fe}_{2} \mathrm{TiO}_{5}$ interfacial layer. Compared with the reported $\mathrm{TiO}_{2}-\mathrm{Fe}_{2} \mathrm{O}_{3}$ hybrid nanostructures (Table S1), the photocurrent density of the TFF inverse opal has a distinct advantage that may be due to the unique sandwich structure and highly efficient charge separation at the heterogeneous interfaces. The photocurrent density against $\mathrm{Fe}_{2} \mathrm{O}_{3}$ cover density on the TFF surface increased from 0.33 to $0.54 \mathrm{~mA} \mathrm{~cm}^{-2}$, and dropped to $0.06 \mathrm{~mA} \mathrm{~cm}^{-2}$ at $1.23 \mathrm{~V}$ vs. RHE when the amount of $\mathrm{FeCl}_{3}$ precursor used during the hydrothermal process increased from 10 to $20 \mathrm{mmol} \mathrm{L}^{-1}$ and then adjusted to $30 \mathrm{mmol} \mathrm{L}^{-1}$. The change in photocurrent density might be caused by the surface light absorption. More densely $\mathrm{Fe}_{2} \mathrm{O}_{3}$ nanorods on the TFF inverse opal may decrease the diffuse reflectance and lead to a lower absorption of the scattered photons. The amperometric currenttime $(I-t)$ curves obtained at $1.23 \mathrm{~V} v s$. RHE with chopped light illumination are displayed in Fig. S6. As seen, the photoresponse promptness and reproduction of the TFF-20 sample is very stable, indicating efficient carrier separation and interfacial charge transport. Fig. $3 \mathrm{~b}$ shows the photoconversion efficiency $(\eta)$ of the TF and TFF inverse opal photoanodes. The calculated $\eta$ value was as high as $0.06 \%$ at $1.0 \mathrm{~V} v$ s. RHE for the TFF inverse opal photoanode, but it was only $0.001 \%$ for the TF inverse opal photoanode at the same potential. The decay in photocurrent density for the TF inverse opal photoanode can reach $50 \%$ in contrast to $6.9 \%$ photocurrent loss of the TFF inverse opal photoanode under 10 -h continuous illumination, as shown in Fig. 3c, indicating that the TFF inverse opal photoanode had remarkable photoactivity and photostability.

Fig. 3d presents the incident photon-to-current efficiency (IPCE) spectra of the TF inverse opal and TFF inverse opal obtained at $1.23 \mathrm{~V}$ vs. RHE. The TF inverse opal showed very low IPCE values over the entire wavelength range. In contrast, the TFF inverse opal photoelectrode showed much higher IPCE values from 365 to $600 \mathrm{~nm}$, indicating the enhancement of charge separation and transfer, boosted by the $\mathrm{Fe}_{2} \mathrm{TiO}_{5}$ interfacial layer. The maximum IPCE value of $6.5 \%$ can be achieved at $365 \mathrm{~nm}$ for the TFF inverse opal photoelectrode, which is five times that of the TF sample $(1.3 \%)$. To clarify the effects of $\mathrm{Fe}_{2} \mathrm{TiO}_{5}$ interfacial layer on charge transfer, EIS measurements were carried out under simulated solar light illumination as shown in Fig. 3e, f. The TFF inverse opal photoelectrode displayed a smaller arc radius at high frequencies of the Nyquist plots, suggesting lower charge transfer resistance $\left(R_{\mathrm{ct}}\right)[36,37]$. Furthermore, the $R_{\mathrm{ct}}$ values were obtained from the equivalent circuit model based on the EIS data (Fig. $3 \mathrm{f}$ ). The value was as low as $497 \Omega$ for the TFF photoelectrode in contrast to $26,640 \Omega$ of the TFF photoelectrode. The results suggested that the TFF inverse opal with the $\mathrm{Fe}_{2} \mathrm{TiO}_{5}$ interfacial layer enabled high efficiency charge transfer and separation for PEC water splitting.

The interfacial charge transfer and recombination kinetics of the TFF photoelectrodes were further investigated by IMPS, as shown in Fig. 4 and Fig. S7. Fig. 4a shows the typical IMPS responses of the TF and TFF inverse opal photoelectrodes. The negative semicircle of the TFF electrode is obviously smaller than that of the TF electrode, indicating that a large fraction of the holes arrived at the semiconductor surface for water oxidation. Importantly, the charge transfer rate constant $\left(k_{\text {tran }}\right)$, the recombination rate constant $\left(k_{\text {trans }}\right)$ and the recombination rate constant $\left(k_{\text {rec }}\right)$ can be calculated by the ratio of the low-frequency imaginary photocurrents (LFIP) to the high-frequency imaginary photocurrents (HFIP) (Fig. 4b) $[38,39]$ as follows:

$K_{\text {trans }} /\left(K_{\text {trans }}+K_{\text {rec }}\right)=$ LFIP/HFIP,

$K_{\text {trans }}+K_{\text {rec }}=2 \pi f_{\text {max }}$.

The ratio of LFIP/HFIP for the TFF electrode is much higher
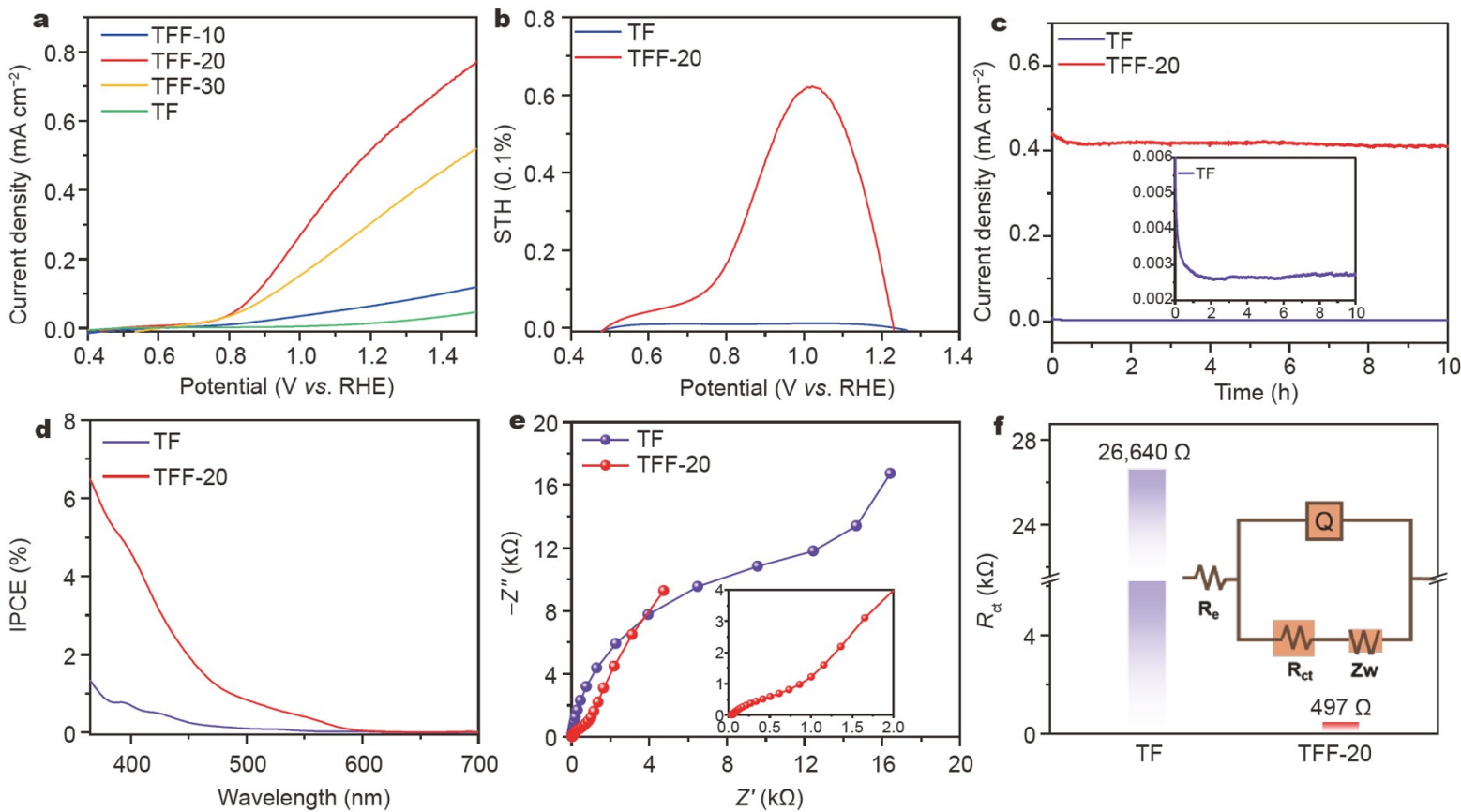

Figure 3 LSV curves of different TF and TFF samples under AM $1.5 \mathrm{G}$ with a scan rate of $10 \mathrm{mV} \mathrm{s}^{-1}$ (a), conversion efficiency curves (b), $I$ - $t$ curves measured at $1.23 \mathrm{~V}$ vs. RHE (c), IPCE spectra (d), EIS curves obtained under simulated sunlight (e), and equivalent circuit model (f) of the TF and TFF-20 samples. 

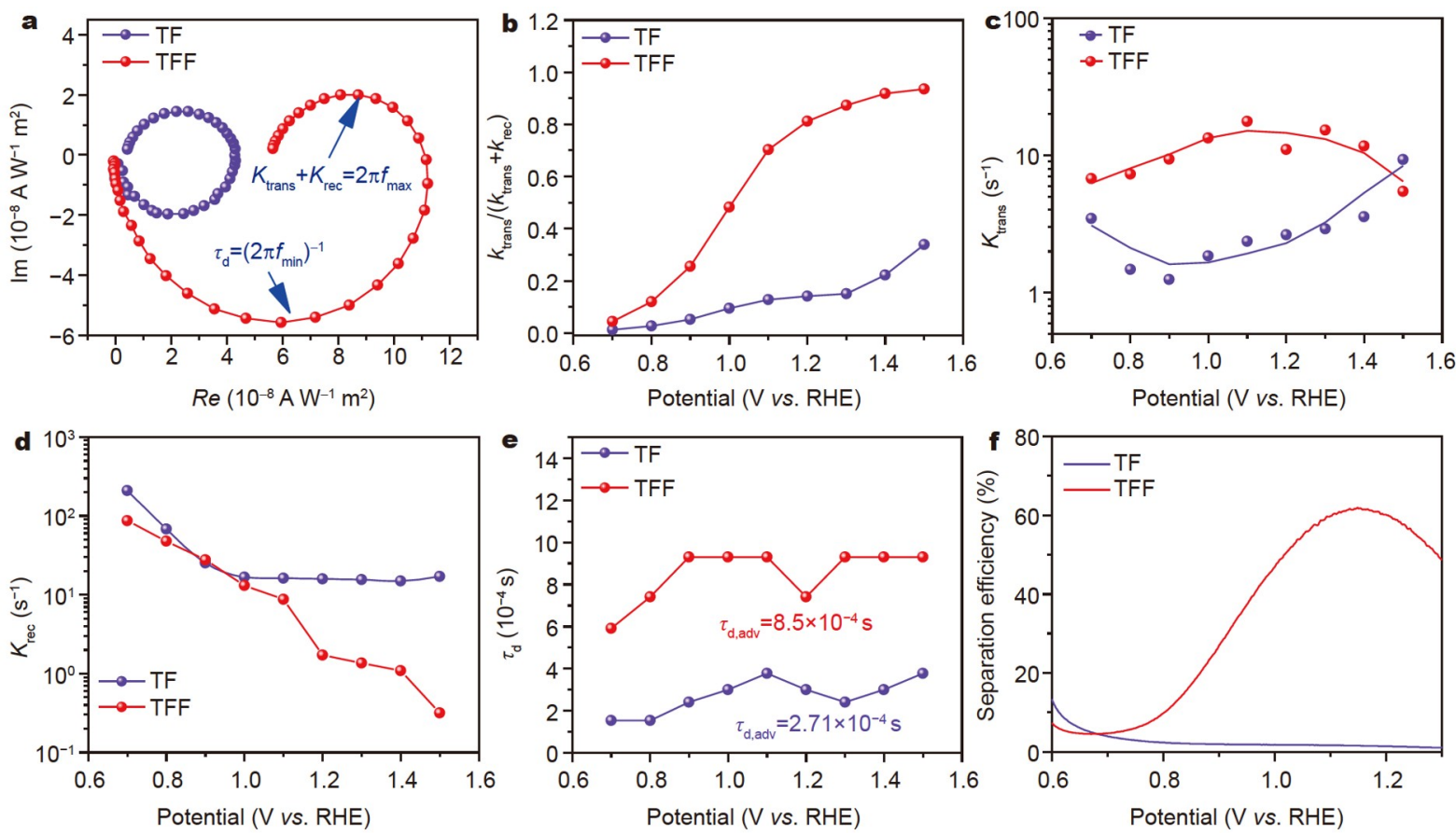

Figure 4 IMPS response recorded at $1.80 \mathrm{~V} v s$. RHE (a); $k_{\text {trans }} /\left(k_{\text {rec }}+k_{\text {trans }}\right)(\mathrm{b}), k_{\text {trans }}(\mathrm{c}), k_{\text {rec }}(\mathrm{d}), \tau_{\mathrm{d}}(\mathrm{e})$, and separation efficiency (f) of different anodes extracted from IMPS analysis.

than that of the TF in the potential range of $0.7-1.5 \mathrm{~V} v s$. RHE, suggesting low bulk carrier recombination inside the TFF electrode with the assistance of the $\mathrm{Fe}_{2} \mathrm{TiO}_{5}$ interfacial layer. Fig. $4 \mathrm{c}$ shows the $k_{\text {trans }}$ curves of the as-prepared samples at different potentials. The charge transfer rate in the TFF electrode is $2-8$ times higher than that of TF electrode at the potential range of $0.7-1.5 \mathrm{~V} v s$. RHE, implying significantly improved bulk charge transport kinetics by the $\mathrm{Fe}_{2} \mathrm{TiO}_{5}$ interface layer within the TFF electrode. Meanwhile, the TFF electrode also achieved lower $k_{\text {rec }}$ performance, and the values sharply decreased with potential increases, thus further demonstrating that the electron-hole recombination behavior is largely suppressed even under high bias voltage (Fig. 4d). The photoelectron lifetime can be obtained from the minimum radial frequency value of the IMPS curves based on the following equation:

$\tau_{\mathrm{d}}=\left(2 \pi f_{\min }\right)^{-1}$.

As displayed in Fig. 4e, the average electron lifetime of the TFF electrode is as high as $8.5 \times 10^{-4} \mathrm{~s}$, which is apparently longer than that of TF electrode $\left(2.71 \times 10^{-4} \mathrm{~s}\right)$. The prolonged $\tau_{\mathrm{d}}$ indicated that the engineered $\mathrm{Fe}_{2} \mathrm{TiO}_{5}$ interfacial layer facilitated electron-hole transfer and separation. A longer electron lifetime, leads to a more powerful PEC activity. The quantitative analysis of the bulk charge recombination of the obtained photoelectrode was evaluated by the hole scavenges, such as $\mathrm{H}_{2} \mathrm{O}_{2}$ [40]. Fig. $4 \mathrm{f}$ shows the separation efficiency against the applied potentials. The maximum separation efficiency is $61.0 \%$ at $1.15 \mathrm{~V} v s$. RHE for the TFF electrode with the $\mathrm{Fe}_{2} \mathrm{TiO}_{5}$ interfacial layer. However, the value is only ca. $5.0 \%$ for the TF electrode. This large difference means that the photo-excited electron-hole can be effectively separated by the $\mathrm{Fe}_{2} \mathrm{TiO}_{5}$ interfacial layer to improve the PEC performance.

Based on these discussions, the remarkable improvement of PEC performance is mainly aroused by interfacial engineering, suppressing bulk carrier recombination, and promoting interfacial charge transfer. The overall effects of interfacial engineering on carrier transfer pathways are schematically summarized in Fig. 5 and Fig. S8. In the TF sample, the large thermal boundary resistance and poor carrier transfer kinetics aroused by the solid Ohmic contact interface result in photogenerated electron-hole recombination and limited transfer to the electrode/electrolyte interface for PEC water splitting (Fig. 5a). By introducing the $\mathrm{Fe}_{2} \mathrm{TiO}_{5}$ interfacial layer between the $\mathrm{TiO}_{2}$ and $\mathrm{Fe}_{2} \mathrm{O}_{3}$ (Fig. 5b), the strong interface coupling effect and the upshift Fermi levels regulate their electronic band structure and generate a hole conduction pathway to promote carrier transfer and suppress charge recombination. XAFS measurements demonstrate strong interface coupling interactions within the TFF electrodes. IMPS and EIS curves also confirm the decrease in interfacial energy barriers. The $\mathrm{Fe}_{2} \mathrm{TiO}_{5}$ interfacial layer promotes the charge transfer from $\mathrm{Fe}_{2} \mathrm{O}_{3}$ to $\mathrm{TiO}_{2}$ due to energy level differences. These features collectively contribute to satisfactory charge separation efficiency of the TFF electrode under illumination. The high charge separation in TFF occurs through three sequential steps: suppressed bulk recombination, prolonged photoelectron lifetime and rapid interfacial transfer involving charge consumption (Fig. 5c). Here, interfacial engineering facilitates interfacial charge transfer, suppresses the bulk carrier recombination and prolongs the photoelectron lifetime, thus boosting the PEC performance.

\section{CONCLUSIONS}

In summary, 3D hierarchical TFF inverse opals have been successfully designed and synthesized via in situ thermal solid reactions for efficient solar water splitting. The $\mathrm{Fe}_{2} \mathrm{TiO}_{5}$ interfacial layer within TFF inverse opals significantly reduces the thermal boundary resistance, and suppresses bulk carrier recombination to promote interfacial charge transfer. The 

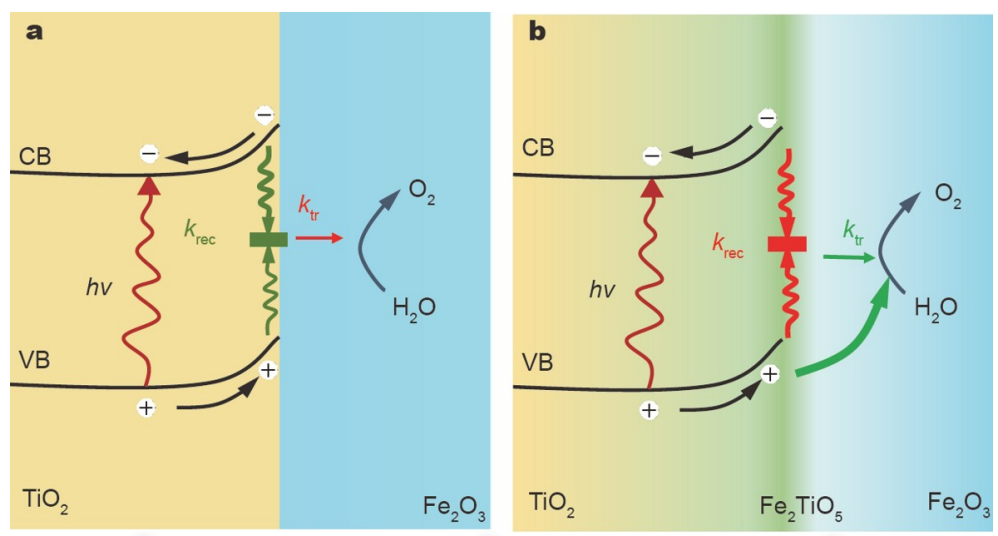

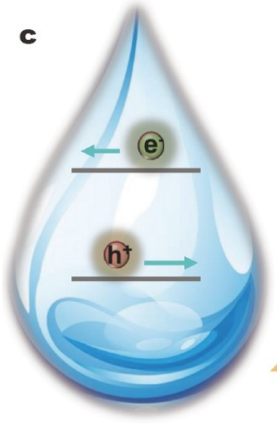

Photoelectron lifetime

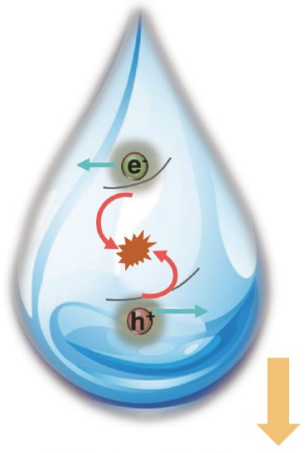

Bulk recombination

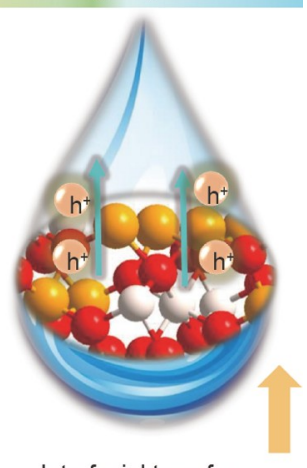

Interfacial transfer

Figure 5 The schematic diagram of the carrier transfer pathways in TF (a) and TFF-20 (b) samples, and the charge separation via sequential steps in TFF-20 sample (c).

improvement of separation efficiency of TFF inverse opals is due to the prolonged photoelectron lifetime, leading to a highly efficient PEC performance. This work highlights the important role of interfacial engineering in charge transfer and provides a valuable insight for the rational design of novel photoelectrodes.

Received 5 April 2021; accepted 1 June 2021;

published online 6 August 2021

1 Gong J, Li C, Wasielewski MR. Advances in solar energy conversion. Chem Soc Rev, 2019, 48: 1862-1864

2 Wang Z, Li C, Domen K. Recent developments in heterogeneous photocatalysts for solar-driven overall water splitting. Chem Soc Rev, 2019, 48: 2109-2125

3 Wang Z, Wang L. Photoelectrode for water splitting: Materials, fabrication and characterization. Sci China Mater, 2018, 61: 806-821

4 Zhang J, Sui R, Xue Y, et al. Direct synthesis of parallel doped N-MoP/ $\mathrm{N}-\mathrm{CNT}$ as highly active hydrogen evolution reaction catalyst. Sci China Mater, 2018, 62: 690-698

5 Zhang $\mathrm{M}$, Wang J, Xue $\mathrm{H}$, et al. Acceptor-doping accelerated charge separation in $\mathrm{Cu}_{2} \mathrm{O}$ photocathode for photoelectrochemical water splitting: Theoretical and experimental studies. Angew Chem Int Ed, 2020, 59: 18463-18467

6 Low J, Yu J, Jaroniec M, et al. Heterojunction photocatalysts. Adv Mater, 2017, 29: 1601694

7 Kim YB, Jung SH, Kim DS, et al. Interleaved biphasic p-n blended copper indium selenide photoelectrode and its application in pulsedriven photoelectrochemical water splitting. Appl Catal B-Environ, 2021, 285: 119839

8 Wang H, Naghadeh SB, Li C, et al. Enhanced photoelectrochemical and photocatalytic activities of CdS nanowires by surface modification with $\mathrm{MoS}_{2}$ nanosheets. Sci China Mater, 2018, 61: 839-850

9 Feng D, Qu J, Zhang R, et al. ITO regulated high-performance n-Si/ ITO/ $\alpha-\mathrm{Fe}_{2} \mathrm{O}_{3} \mathrm{Z}$-scheme heterostructure towards photoelectrochemical water splitting. J Catal, 2020, 381: 501-507

10 Zhuang G, Chen Y, Zhuang Z, et al. Oxygen vacancies in metal oxides: Recent progress towards advanced catalyst design. Sci China Mater, 2020, 63: 2089-2118

11 Xu W, Tian W, Meng L, et al. Interfacial chemical bond-modulated Zscheme charge transfer for efficient photoelectrochemical water splitting. Adv Energy Mater, 2021, 11: 2003500

12 Zhang J, Zhang Q, Feng X. Support and interface effects in watersplitting electrocatalysts. Adv Mater, 2019, 31: 1808167

$13 \mathrm{Hu} \mathrm{L}$, Zeng $\mathrm{X}$, Wei $\mathrm{X}$, et al. Interface engineering for enhancing electrocatalytic oxygen evolution of NiFe $\mathrm{LDH} / \mathrm{NiTe}$ heterostructures. Appl Catal B-Environ, 2020, 273: 119014

14 Chou TM, Chan SW, Lin YJ, et al. A highly efficient Au-MoS ${ }_{2}$ nanocatalyst for tunable piezocatalytic and photocatalytic water disinfection. Nano Energy, 2019, 57: 14-21

15 Zeng $\mathrm{Y}$, Yang $\mathrm{T}$, Li C, et al. $\mathrm{Zn}_{x} \mathrm{Cd}_{1-x} \mathrm{Se}$ nanoparticles decorated ordered mesoporous $\mathrm{ZnO}$ inverse opal with binder-free heterojunction interfaces for highly efficient photoelectrochemical water splitting. Appl Catal B-Environ, 2019, 245: 469-476

16 Chen $\mathrm{Y}, \mathrm{Li} \mathrm{L}, \mathrm{Xu} \mathrm{Q}$, et al. Recent advances in opal/inverted opal photonic crystal photocatalysts. Sol RRL, 2021, 5: 2000541

17 Hoang S, Gao PX. Nanowire array structures for photocatalytic energy conversion and utilization: A review of design concepts, assembly and integration, and function enabling. Adv Energy Mater, 2016, 6: 1600683

18 Wang X, Liow C, Bisht A, et al. Engineering interfacial photo-induced charge transfer based on nanobamboo array architecture for efficient solar-to-chemical energy conversion. Adv Mater, 2015, 27: 2207-2214

19 Lin S, Zhang N, Wang F, et al. Carbon vacancy mediated incorporation of $\mathrm{Ti}_{3} \mathrm{C}_{2}$ quantum dots in a 3D inverse opal g- $\mathrm{C}_{3} \mathrm{~N}_{4}$ Schottky junction catalyst for photocatalytic $\mathrm{H}_{2} \mathrm{O}_{2}$ production. ACS Sustain Chem Eng, 2021, 9: 481-488

20 Liu GQ, Li Y, Yang Y, et al. Anti-photocorrosive photoanode with rGo/ PdS as hole extraction layer. Sci China Mater, 2020, 63: 1939-1947

21 Wang W, Jin C, Qi L. Hierarchical CdS nanorod@ $\mathrm{SnO}_{2}$ nanobowl arrays for efficient and stable photoelectrochemical hydrogen generation. 


\section{Small, 2018, 14: 1801352}

22 Tang S, Li M, Huang D, et al. 3D hierarchical nanorod@nanobowl array photoanode with a tunable light-trapping cutoff and bottomselective field enhancement for efficient solar water splitting. Small, 2019, 15: 1804976

23 Wang $\mathrm{W}$, Dong $\mathrm{J}$, Ye $\mathrm{X}$, et al. Heterostructured $\mathrm{TiO}_{2}$ nanorod@nanobowl arrays for efficient photoelectrochemical water splitting. Small, 2016, 12: 1469-1478

24 Zhang $\mathrm{H}$, Zhou W, Yang $\mathrm{Y}$, et al. 3D $\mathrm{WO}_{3} / \mathrm{BiVO}_{4} / \mathrm{cobalt}$ phosphate composites inverse opal photoanode for efficient photoelectrochemical water splitting. Small, 2017, 13: 1603840

25 Wang Z, Li X, Ling $\mathrm{H}$, et al. 3D FTO/FTO-nanocrystal/TiO $\mathrm{T}_{2}$ composite inverse opal photoanode for efficient photoelectrochemical water splitting. Small, 2018, 14: 1800395

26 Yang $\mathrm{T}$, Xue J, Tan $\mathrm{H}$, et al. Highly ordered $\mathrm{ZnO} / \mathrm{ZnFe}_{2} \mathrm{O}_{4}$ inverse opals with binder-free heterojunction interfaces for high-performance photoelectrochemical water splitting. J Mater Chem A, 2018, 6: 1210-1218

27 Zeng $\mathrm{Y}$, Xue J, He M, et al. Investigation of interfacial charge transfer in $\mathrm{Cu}_{x} \mathrm{O} @ \mathrm{TiO}_{2}$ heterojunction nanowire arrays towards highly efficient solar water splitting. Electrochim Acta, 2021, 367: 137426

28 Deng $\mathrm{Y}$, Xing $\mathrm{M}$, Zhang J. An advanced $\mathrm{TiO}_{2} / \mathrm{Fe}_{2} \mathrm{TiO}_{5} / \mathrm{Fe}_{2} \mathrm{O}_{3}$ tripleheterojunction with enhanced and stable visible-light-driven fenton reaction for the removal of organic pollutants. Appl Catal B-Environ, 2017, 211: 157-166

29 Zhang X, Liu Y, Lee ST, et al. Coupling surface plasmon resonance of gold nanoparticles with slow-photon-effect of $\mathrm{TiO}_{2}$ photonic crystals for synergistically enhanced photoelectrochemical water splitting. Energy Environ Sci, 2014, 7: 1409

30 Li C, Wang T, Luo Z, et al. Enhanced charge separation through ALDmodified $\mathrm{Fe}_{2} \mathrm{O}_{3} / \mathrm{Fe}_{2} \mathrm{TiO}_{5}$ nanorod heterojunction for photoelectrochemical water oxidation. Small, 2016, 12: 3415-3422

31 Chen S, Zeng Q, Bai J, et al. Preparation of hematite with an ultrathin iron titanate layer via an in situ reaction and its stable, long-lived, and excellent photoelectrochemical performance. Appl Catal B-Environ, 2017, 218: 690-699

32 Deng J, Zhang Q, Lv X, et al. Understanding photoelectrochemical water oxidation with X-ray absorption spectroscopy. ACS Energy Lett, 2020, 5: 975-993

33 Lv X, Nie K, Lan $\mathrm{H}$, et al. $\mathrm{Fe}_{2} \mathrm{TiO}_{5}$-incorporated hematite with surface p-modification for high-efficiency solar water splitting. Nano Energy, 2017, 32: 526-532

34 Deng J, Lv X, Liu J, et al. Thin-layer $\mathrm{Fe}_{2} \mathrm{TiO}_{5}$ on hematite for efficient solar water oxidation. ACS Nano, 2015, 9: 5348-5356

35 Shi C, Ye S, Wang X, et al. Modular construction of Prussian blue analog and $\mathrm{TiO}_{2}$ dual-compartment Janus nanoreactor for efficient photocatalytic water splitting. Adv Sci, 2021, 8: 2001987

36 Feng J, Zhao X, Zhang B, et al. Sol-gel synthesis of highly reproducible $\mathrm{WO}_{3}$ photoanodes for solar water oxidation. Sci China Mater, 2020, 63: 2261-2271

37 Zhu S, Wang Z, Huang F, et al. Hierarchical $\mathrm{Cu}(\mathrm{OH})_{2} @ \mathrm{Ni}_{2}(\mathrm{OH})_{2} \mathrm{CO}_{3}$ core/shell nanowire arrays in situ grown on three-dimensional copper foam for high-performance solid-state supercapacitors. J Mater Chem A, 2017, 5: 9960-9969

38 Yu F, Li F, Yao T, et al. Fabrication and kinetic study of a ferrihydritemodified $\mathrm{BiVO}_{4}$ photoanode. ACS Catal, 2017, 7: 1868-1874

39 Thorne JE, Jang JW, Liu EY, et al. Understanding the origin of photoelectrode performance enhancement by probing surface kinetics. Chem Sci, 2016, 7: 3347-3354

40 Deng J, Lv X, Nie K, et al. Lowering the onset potential of $\mathrm{Fe}_{2} \mathrm{TiO}_{5} /$ $\mathrm{Fe}_{2} \mathrm{O}_{3}$ photoanodes by interface structures: $\mathrm{F}$ - and Rh-based treatments. ACS Catal, 2017, 7: 4062-4069

Acknowledgements This work was supported by the National Natural Science Foundation of China (21771001 and 51872002), Anhui Provincial Natural Science Foundation (1708085ME120), the Program of Anhui Scientific and Technical Leaders Reserve Candidates (2018RH168), the Scholar Program for the Outstanding Innovative Talent of College Discipline (Specialty), and the doctoral start-up fund and open fund for Discipline Con- struction, Institute of Physical Science and Information Technology, Anhui University.

Author contributions Zhang M, Liu P, Tan $\mathrm{H}$ and Li S designed the research; Zhang M, Liu P, Zhang H, Huang F, Zhang K and Li S synthesized the samples, performed the current-potential curve, XRD, UV-vis spectra, SEM and IPCE measurements; all authors discussed the results and co-wrote the paper.

Conflict of interest The authors declare that they have no conflict of interest.

Supplementary information Supporting data are available in the online version of the paper.

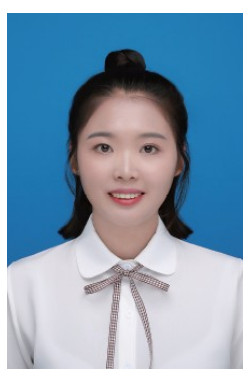

Miaomiao Zhang received her BSc degree in applied chemistry from Anhui Jianzhu University. She is currently pursuing her MSc degree at Anhui University under the supervision of Prof. Shikuo Li. Her research focuses on the interfacial catalysis.

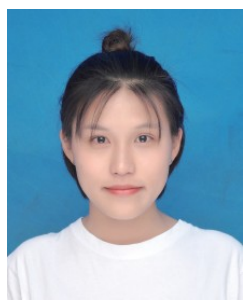

Pianpian Liu obtained her BSc degree in chemical engineering and technology from Huainan Normal College. Then she joined Anhui University and conducted research under the supervision of Prof. Shikuo Li. Her research interest is designing porous nanostructures for investigating interfacial catalysis.

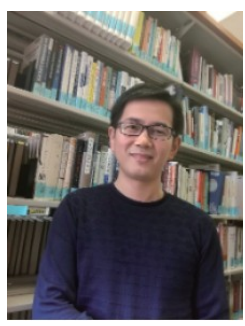

Shikuo Li received his BSc degree from Anhui University in 2004, and $\mathrm{PhD}$ degree from the University of Science and Technology of China in 2017. He joined the Department of Chemistry at the University of Pittsburgh as a visiting scholar in 2018. Since Dec 2020, he has been a full professor of materials science and chemistry at the School of Chemistry and Chemical Engineering, Anhui University. His current research interest is developing novel nanostructures for photoelectrochemistry.

\section{光子晶体异质界面工程调控光生载流子分离及高效 水分解性能研究}

张苗苗 ${ }^{1 \dagger}$, 刘翩翩 ${ }^{1 \dagger}$, 谈浩 ${ }^{2}, 弓$ 惠 $^{1}$, 黄方志 ${ }^{{ }^{*}}$, 张坤 ${ }^{3}$, 李士阔 $^{1 *}$

摘要 活性材料中的载流子转移是太阳能高效利用的一大挑战. 本文 通过固相反应原位制备了三维多孔 $\mathrm{TiO}_{2} / \mathrm{Fe}_{2} \mathrm{TiO}_{5} / \mathrm{Fe}_{2} \mathrm{O}_{3}$ (TFF) 反蛋白石 结构, 用于光电化学分解水. $\mathrm{Fe}_{2} \mathrm{TiO}_{5}$ 作为桥接层与 $\mathrm{TiO}_{2}$ 和 $\mathrm{Fe}_{2} \mathrm{O}_{3}$ 紧密相 连, 降低了界面电荷转移电阻, 抑制了体相载流子复合. 优化后的 TFF在 $1.23 \mathrm{~V}$ (相对于可逆氢电极) 的光电流密度为 $0.54 \mathrm{~mA} \mathrm{~cm}$, 是 $\mathrm{TiO}_{2} / \mathrm{Fe}_{2} \mathrm{O}_{3}$ ( TF) 反蛋白石结构 $\left(0.02 \mathrm{~mA} \mathrm{~cm}^{-2}\right)$ 的 25 倍. 在偏压范围为 $0.7-1.5 \mathrm{~V}$ (相 对于可逆氢电极) 时, TFF光阳极的电荷转移速率是TF的 $2-8$ 倍. 此外, 我们通过X射线吸收光谱和强度调制光电流光谱进一步探索了 $\mathrm{Fe}_{2} \mathrm{TiO}_{5}$ 对界面电荷传输动力学的影响. 该工作为揭示界面工程对光生电荷分 离和转移的调控作用, 设计开发高效的界面异质结构光电极提供了一 种新策略. 